\title{
Cardiac myxoma misdiagnosed as infective endocarditis: a case of Carney complex
}

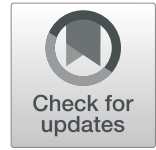

\author{
Chang Hun Kim, Hyung Gon Je ${ }^{*}$ (D), Min Ho Ju and Chee-Hoon Lee
}

\begin{abstract}
Background: Infective endocarditis and cardiac myxoma have common features including fever, systemic embolism and intra-cardiac masses. For this reason, these diseases are often misdiagnosed one for another despite proper imaging studies. Herein, we report a case of suspected infective endocarditis in a patient with acute stroke, fever and a mass adjacent to the mitral valve.

Case presentation: A 24-year-old male patient presented with recurrent fever and stroke. In view of a history of Cushing syndrome and a mobile mass in the left atrium, infective endocarditis was highly suspected. He was transferred for emergency cardiac surgical intervention. During surgery, intraoperative transesophageal echocardiography revealed a $7 \mathrm{~cm}$ mass attached to the interatrial septum. The mass was excised through right mini-thoracotomy and pathological examination confirmed the presence of a myxoma. Based on the above clinical findings and genetic analysis, the diagnosis of Carney complex was confirmed.

Conclusions: Infective endocarditis and cardiac myxoma have common features and can be misdiagnosed. If a young patient presenting with embolic stroke had a history of an endocrine neoplasm, Carney complex should be considered in the differential diagnosis of infective endocarditis.
\end{abstract}

Keywords: Myxoma, Infective endocarditis, Cerebral infarction, Cushing syndrome, Carney complex

\section{Background}

At least $20 \%$ of all ischemic strokes originate in the heart. Especially, young patients presenting with acute stroke should be evaluated for an intra-cardiac source of embolism. Among them, infective endocarditis (IE) and cardiac myxoma $(\mathrm{CM})$ share common features such as fever, systemic embolism, and an intra-cardiac mass. A recent publication also showed a case of $\mathrm{CM}$ initially misdiagnosed as IE [1]. These diseases can be easily diagnosed using imaging studies, but there is a possibility of misdiagnosis. We report a case of suspected IE in a patient with recurrent fever, acute stroke, and a mass adjacent to the mitral valve.

\footnotetext{
* Correspondence: jehg7332@gmail.com

Department of Thoracic and Cardiovascular Surgery, Pusan National University Yangsan Hospital, Medical Research Institute of Pusan National University, Geumo-ro 20, Beomeo-ri, Mulgeum-eup, Yangsan-si, Gyeongsangnam-do 50612, Republic of Korea
}

\section{Case presentation}

A 24-year old male patient visited the emergency department of a tertiary hospital for increased drowsiness and fever. The patient had a history of Cushing's syndrome (Fig. 1a) and had been on long-term steroid replacement therapy after resection of a functioning adrenal adenoma 4 years ago. Multiple cerebral infarcts were revealed on brain magnetic resonance imaging (Fig. 1b, c). He was treated with intravenous tissue plasminogen activator (tPA) and mechanical thrombectomy of the left middle cerebral artery. To identify the source of the cerebral embolism, transthoracic echocardiography (TTE) was performed and a large, $4 \mathrm{~cm}$ sized, highly mobile mass adjacent to the mitral valve was revealed. After cerebral intervention, the patient presented recurrent fever and hypotension. Based on the patient's grossly Cushing's features, long history of steroid usage, fever and hypotension, the cardiologist in the referral hospital

(c) The Author(s). 2020 Open Access This article is licensed under a Creative Commons Attribution 4.0 International License, which permits use, sharing, adaptation, distribution and reproduction in any medium or format, as long as you give appropriate credit to the original author(s) and the source, provide a link to the Creative Commons licence, and indicate if changes were made. The images or other third party material in this article are included in the article's Creative Commons licence, unless indicated otherwise in a credit line to the material. If material is not included in the article's Creative Commons licence and your intended use is not permitted by statutory regulation or exceeds the permitted use, you will need to obtain permission directly from the copyright holder. To view a copy of this licence, visit http://creativecommons.org/licenses/by/4.0/ The Creative Commons Public Domain Dedication waiver (http://creativecommons.org/publicdomain/zero/1.0/) applies to the data made available in this article, unless otherwise stated in a credit line to the data. 


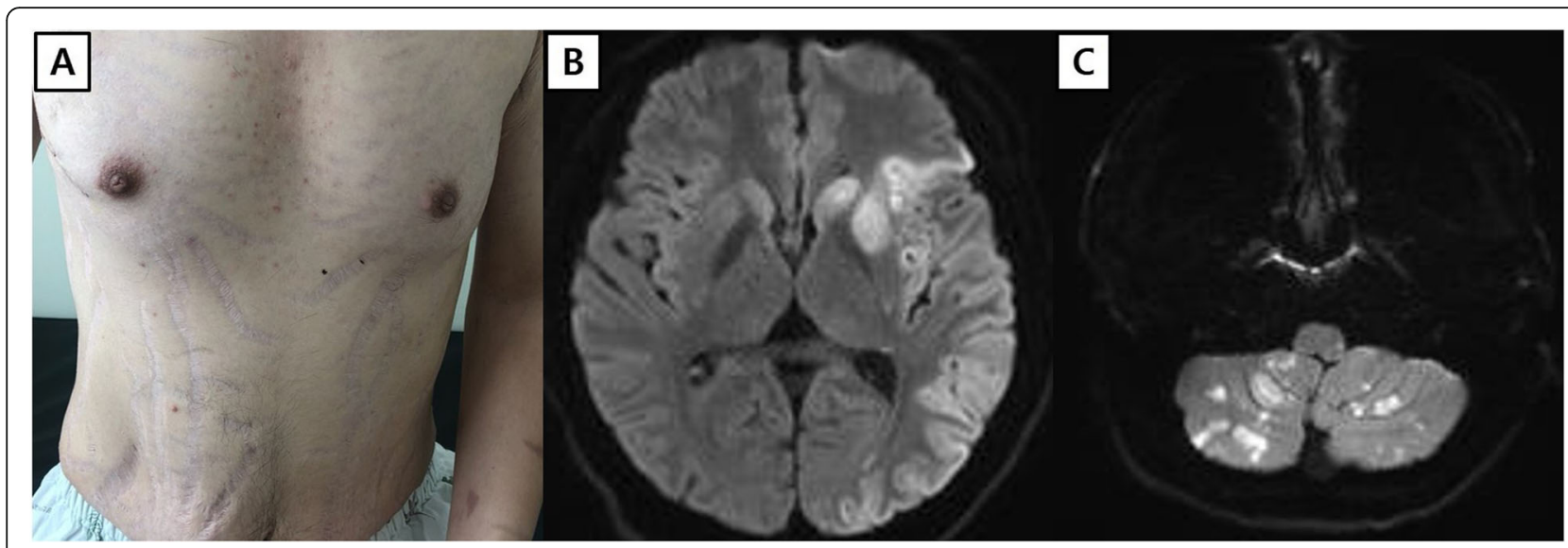

Fig. 1 The torso of the patient shows skin striae due to Cushing's syndrome (a). Magnetic resonance images show acute infarction on the area of left middle cerebral artery (b) and both cerebellum (c)

highly suspected an IE. For treatment with minimally invasive cardiac surgery, they transferred the patient to our hospital. Upon arrival, he experienced drowsiness and aphasia and his Glasgow Coma Scale (GCS) was recorded at 12/15 (eyes 3 , verbal 4 , motor 5). The patient presented stable vital signs except mild fever of $37.1^{\circ} \mathrm{C}$. Lab results showed neutrophil-dominant leukocytosis and elevated C-reactive protein (CRP) of 15.19. On account of the potential systemic effects of tPA and risk of hemorrhagic transformation in the area of cerebral infarction, surgery was deferred for $48 \mathrm{~h}$. He was managed with intravenous antibiotics. For further evaluation, we tried transesophageal echocardiography, but the patient's unclear mentality interfered with the test.

During surgery, intraoperative transesophageal echocardiography (TEE) revealed that the mass was not attached to the mitral valve but to the interatrial septum (Fig. 2a). The mass was found obstructing the mitral inflow, leading to functional mitral stenosis (Fig. 2b). We considered the possibility that the mass might be a tumor (possibly $\mathrm{CM}$ ) rather than a vegetation due to IE. A 6-cm right mini-thoracotomy was performed along the fourth intercostal space, and a cannula was inserted through the right femoral artery and vein (17 Fr and 23 Fr, Edwards Lifescience, Irvine, CA, USA). After aortic cross-clamping with the Glauber clamp (Cardiomedical $\mathrm{GmbH}$, Langenhagen, Germany), cardioplegic arrest was induced with antegrade cold blood cardioplegia. Through the left atriotomy, complete excision of the mass with its stalk and adjacent endocardium was achieved. The mass was $7 \mathrm{~cm}$ in size, friable, and multilobulated (Fig. 2c). Cardiopulmonary bypass and aortic cross-clamping took 35 and $17 \mathrm{~min}$, respectively. After surgery, mitral valve stenosis or regurgitation was not observed. The patient was extubated $6 \mathrm{~h}$ postoperatively and transferred to the ward the next day. Postoperative TTE showed no remnant mass in the left atrium and an intact interatrial septum. The drowsiness and aphasia

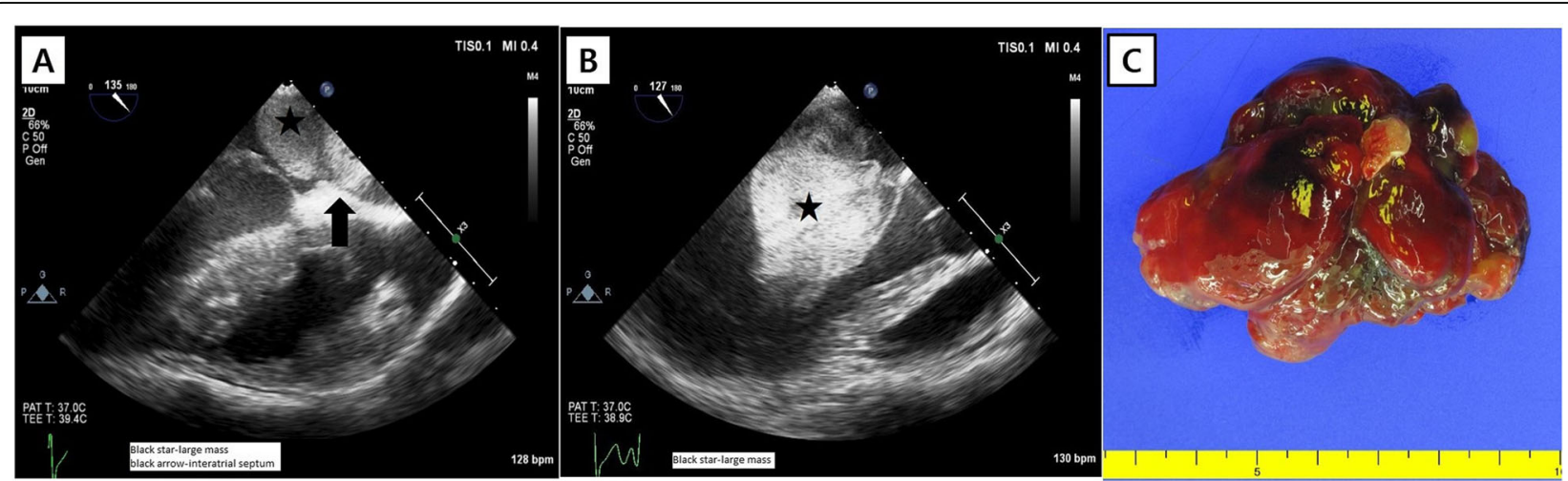

Fig. 2 Transesophageal echocardiography shows a large mass (black star) attached to the interatrial septum (black arrow) (a), which protrudes into the mitral valve (b). The gross specimen of the excised mass is shown (c) 
gradually improved. He was transferred to the Department of Neurology for further management of his neurological sequelae. Pathologic examination confirmed the diagnosis of a myxoma. Carney complex $(\mathrm{CNC})$ was suspected because of the history of endocrine neoplasm and CM. Genetic analysis confirmed the presence of a mutation in the PPKAR1A gene. Therefore, he was finally diagnosed with CNC presenting with $\mathrm{CM}$ and systemic embolism.

\section{Discussion and conclusions}

In the present case, symptoms and signs such as skin striae in the torso, relapsing fever, a highly mobile mass on the mitral valve, and embolic cerebral infarction led to a high level of suspicion for IE. Additionally, the immunocompromised state due to long-term steroid replacement therapy supported the probability of IE. However, intraoperative TEE helped confirm that the mass was attached to the interatrial septum and not to the mitral valve, thereby showing the mass to be a myxoma. CM is the most frequently occurring benign primary cardiac tumor, accounting for $0.3 \%$ of open-heart surgeries [1]. While vegetation in IE is known to cause systemic embolism, cardiac myxoma can also be an important cause of stroke. CM is responsible for $0.5 \%$ of all strokes and $10-30 \%$ of patients with CM were reported to develop cerebral embolic infarction [2]. Although infected CM is a rare condition, it should also be considered in the differential diagnosis of fever and embolism [3]. Therefore, if a patient with cerebral infarction had a cardiac mass, CM as well as IE should be suspected. To make a differential diagnosis, whenever operating on infective lesions, a part of the specimen should be sent to histopathology rather than all of it going to microbiology.

Most cases of $\mathrm{CM}$ are benign and sporadic. Familial forms of myxoma also exist and typically occur in young, male patients in unusual locations, and have a tendency to be multifocal [4]. CNC is a rare autosomal dominant syndrome, characterized by pigmented skin lesions, familial CM forms, and endocrine neoplasms of the adrenocortical, thyroid, or testicular systems [5]. As in the present case, if a patient with CM has a history of endocrine tumors, CNC should be suspected. Surgical resection should be done promptly because of the high risk of complications due to tumoral effects or systemic embolism [6]. Because $\mathrm{CM}$ in $\mathrm{CNC}$ has a high risk of systemic embolism and recurrence, extensive resection including the stalk with adjacent endocardium is advised and periodic TTE during long-term follow up is mandatory $[7,8]$ genetic counseling and education for. Finally, genetic counseling and education for close relatives is also important for the treatment of patients with CNC.
In the present case, the precipitous treatment with intravenous TPA and mechanical thrombectomy delayed surgery. For young patients presenting with stroke, prompt evaluation of the source of embolism should be done prior to stroke treatment. Echocardiography and computed tomography can provide valuable information to help establish a treatment plan and minimize the possibility of additional embolic events.

In summary, infective endocarditis might be suspected in patients with a history of recurrent fever, stroke, and a mobile mass in the left atrium. However, due to similarities in symptoms and signs, Carney complex associated cardiac myxoma should also be included in the differential diagnosis, especially in case of young patients with a history of endocrine neoplasms.

\section{Abbreviations}

IE: Infective endocarditis; CM: Cardiac myxoma; tPA: Tissue plasminogen activator; TTE: Trans-thoracic echocardiogram; TEE: Transesophageal echocardiography; CNC: Carney complex

\section{Acknowledgements}

Not applicable.

\section{Authors' contributions}

All authors have made substantial contributions to the conception of the work; interpretation of data; and have drafted the work. All authors have approved the submitted version and agreed both to be personally accountable for the author's own contributions and to ensure that questions related to the accuracy or integrity of any part of the work, even ones in which the author was not personally involved, are appropriately investigated, resolved, and the resolution documented in the literature.

Funding

Not applicable.

Availability of data and materials

Not applicable.

Ethics approval and consent to participate Not applicable.

Consent for publication

Not applicable.

Competing interests

The authors declare that they have no competing interests.

Received: 3 May 2020 Accepted: 20 July 2020

Published online: 25 July 2020

References

1. Fitzgerald G, Coughlan J, Satti Z, Arnous S. Atrial myxoma presenting as infective endocarditis. BMJ Case Rep. 2018. https://doi.org/10.1136/bcr-2017223656

2. Havrankova E, Stenova E, Olejarova I, Sollarova K, Kinova S. Carney complex with biatrial cardiac myxoma. Ann Thorac Cardiovasc Surg. 2014;20(Suppl): 890-2.

3. Kawabori M, Benkert AR, Warner KG, Patel AR, Arkun K, Chen FY, et al. Uncommon cause of fever and embolism: staphylococcus epidermidis infected myxoma. Ann Thorac Surg. 2019;107:e283.

4. Zheng Z, Guo G, Xu L, Lei L, Wei X, Pan Y. Left atrial myxoma with versus without cerebral embolism: length of symptoms, morphologic characteristics, and outcomes. Tex Heart Inst J. 2014;41:592-5.

5. Carney JA. Differences between nonfamilial and familial cardiac myxoma. Am J Surg Pathol. 1985;9:53-5. 
6. Correa R, Salpea P, Stratakis CA. Carney complex: an update. Eur J Endocrinol. 2015;173:M85-97.

7. Siordia JA. Medical and surgical Management of Carney Complex. J Card Surg. 2015;30:560-7.

8. Carney J. Carney complex: the complex of myxomas, spotty pigmentation, endocrine overactivity, and schwannomas. Semin Dermatol. 1995;14:90-8.

\section{Publisher's Note}

Springer Nature remains neutral with regard to jurisdictional claims in published maps and institutional affiliations.

Ready to submit your research? Choose BMC and benefit from:

- fast, convenient online submission

- thorough peer review by experienced researchers in your field

- rapid publication on acceptance

- support for research data, including large and complex data types

- gold Open Access which fosters wider collaboration and increased citations

- maximum visibility for your research: over $100 \mathrm{M}$ website views per year

At $B M C$, research is always in progress.

Learn more biomedcentral.com/submissions 